ISSN : $2450-766 X$

\title{
PELABELAN L(2,1) PADA OPERASI BEBERAPA KELAS GRAF
}

\author{
S. Fatimah1, I W. Sudarsana², dan S. Musdalifah ${ }^{3}$ \\ 1,2,3 Program Studi Matematika Jurusan Matematika \\ Fakultas Matematika dan IImu Pengetahuan Alam Universitas Tadulako \\ Jalan Sukarno-Hatta Km. 9 Palu 94118, Indonesia \\ 1fatimahs156@ymail.com, 22sudarsanaiwayan@yahoo.co.id, 33selvymusdalifah@yahoo.com
}

\section{ABSTRACT}

Let $\mathrm{G}$ be a graph with $p$ vertices dan $q$ edges. An $\mathrm{L}(2,1)$ labeling of graph $\mathrm{G}$ is a function $f: V \rightarrow\{0,1,2 \cdots, k\}$ such that statisfies the conditions $|f(u)-f(v)| \geq 2$, for $d(u, v)=1$ for $|f(u)-f(v)| \geq 1$, if $d(u, v)=2$. A number $\mathrm{k}$ is called the span of $L(2,1)$ labeling, if $k$ is the largest label vertex of it's labeling. Notation $\lambda(G)$ states that the smallest span of all $L(2,1)$ labelings in a graph $G$. $L^{\prime}(2,1)$ labeling on injective $L(2,1)$ labeling. A minimum span of all labeling $L^{\prime}(2,1)$ denoted by $\lambda^{\prime}(G)$. A graph $G$ which has $L^{\prime}(2,1)$ labeling is called the graph $L^{\prime}(2.1)$. The results showed that fan graph $\left(F_{n}\right)$ with $\lambda^{\prime}\left(F_{n}\right)=n+1$, wheel graph $\left(W_{n}\right)$ with $\lambda^{\prime}\left(W_{n}\right)=n+1$, lotus graph $\left(T_{n}\right)$ with $\lambda^{\prime}\left(T_{n}\right)=2 n+2$, $K_{1} \odot\left(P_{n} \cup F_{n}\right)$ graph with $\lambda^{\prime}\left(K_{1} \odot\left(P_{n} \cup F_{n}\right)\right)=2 n+2$ and $K_{1} \odot t C_{n}$ graph with $\lambda^{\prime}\left(K_{1} \odot t C_{n}\right)=t n+1$ is graph $\mathrm{L}^{\prime}(2,1)$.

Keywords : Fan Graph, Lotus Graph, $L(2,1)$ labeling, $L^{\prime}(2,1)$ labeling, Wheel Graph.

\section{ABSTRAK}

Misalkan $\mathrm{G}$ adalah graf dengan $p$ titik dan $q$ sisi. Pelabelan $\mathrm{L}(2,1)$ pada graf $\mathrm{G}$ adalah fungsi $f: V \rightarrow\{0,1,2 \cdots, k\}$ yang memenuhi kondisi $|f(u)-f(v)| \geq 2$, jika $d(u, v)=1$ dan $|f(u)-f(v)| \geq 1$, jika $d(u, v)=2$. Bilangan $\mathrm{k}$ disebut span dari pelabelan $L(2,1)$, jika $k$ adalah label titik terbesar dari pelabelan $L(2,1)$. Notasi $\lambda(G)$ menyatakan span terkecil atas semua pelabelan $L(2,1)$ pada graf $G$. Pelabelan $L(2,1)$ yang injektif disebut pelabelan $L^{\prime}(2,1)$. Minimum span atas semua pelabelan $L^{\prime}(2,1)$ dinotasikan dengan $\lambda^{\prime}(G)$. Sebuah graf $G$ yang mempunyai pelabelan $\mathrm{L}^{\prime}(2,1)$ dinamakan graf $\mathrm{L}^{\prime}(2,1)$. Dalam penilitian ini, telah berhasil ditunjukkan bahwa graf kipas $\left(F_{n}\right)$ dengan $\lambda^{\prime}\left(F_{n}\right)=$ $n+1$, graf roda $\left(W_{n}\right)$ dengan $\lambda^{\prime}\left(W_{n}\right)=n+1$, graf teratai $\left(T_{n}\right)$ dengan $\lambda^{\prime}\left(T_{n}\right)=2 n+2$, graf $K_{1} \odot\left(P_{n} \cup F_{n}\right)$ dengan $\lambda^{\prime}\left(K_{1} \odot\left(P_{n} \cup F_{n}\right)\right)=2 n+2$ dan graf $K_{1} \odot t C_{n}$ dengan $\lambda^{\prime}\left(K_{1} \odot t C_{n}\right)=t n+1$ adalah graf $\mathrm{L}^{\prime}(2,1)$.

Kata kunci : Graf Kipas, Graf Roda, Graf Teratai, Pelabelan L(2,1), Pelabelan L'(2,1). 


\section{PENDAHULUAN}

Ada banyak jenis pelabelan graf yang telah dikembangkan, diantaranya adalah pelabelan gracefull, pelabelan harmoni, pelabelan super mean, pelabelan ajaib, pelabelan anti ajaib, pelabelan prime cordial, pelabelan triangular dan pelabelan $L(2,1)$.

Pelabelan $\mathrm{L}(2,1)$ didefinisikan sebagai pemberian label pada titik suatu graf dengan fungsi adalah fungsi $f: V \rightarrow N \cup\{0\}$ sehingga mutlak dari selisih label dari dua titik yang bertetangga langsung paling sedikit dua dan mutlak dari dua titik yang berjarak dua selisih labelnya paling sedikit satu. $f: V \rightarrow$ $\{0,1,2 \cdots, k\}$ dimana $\mathrm{k}$ adalah span dari pelabelan $\mathrm{L}(2,1)$. Span adalah label terbesar dari pelabelan $\mathrm{L}(2,1)$ pada graf $\mathrm{G}$ atau $\mathrm{k} \in f(v)$ yang terbesar. Span dari suatu graf $\mathrm{G}$ bisa lebih dari satu. Minimum dari beberapa span graf $G$ dilambangkan dengan $\lambda(G)$. Secara matematis dapat ditulis $\lambda(G)=$ $\min \{\operatorname{span}(G)$ atas semua pelabelan $L(2,1)$ yang dimiliki sebuah graf $G\}$.

Temuan terakhir terkait pelabelan $L(2,1)$ adalah graf lintasan, graf siklus, graf bintang dan graf kincir [4]. Namun, untuk graf kipas, graf roda, graf teratai, graf $K_{1} \odot\left(P_{n} \cup F_{n}\right)$ dan graf $K_{1} \odot t C_{n}$ masih menjadi masalah terbuka.

\section{TINJAUAN PUSTAKA}

\subsection{Definisi Graf}

Graf adalah suatu diagram yang terdiri dari titik-titik (points) yang disebut vertex (node / titik) yang dihubungkan dengan garis yang dinamakan sisi dimana setiap sisi terhubung dengan tepat 2 vertex [5].

\subsection{Jenis - Jenis Graf}

Graf dibagi menjadi beberapa kelas, pada bagian ini ada beberapa jenis - jenis graf yang berkaitan pada penelitian ini.

1. Graf Lengkap

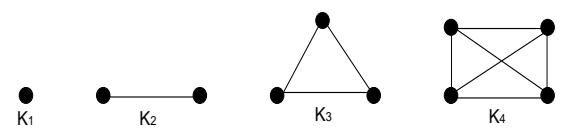

Gambar 1. Contoh graf lengkap

2. Graf Lintasan

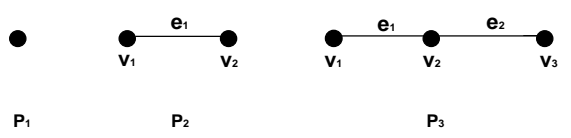

Gambar 2. Contoh graf lintasan 
3. Graf Siklus
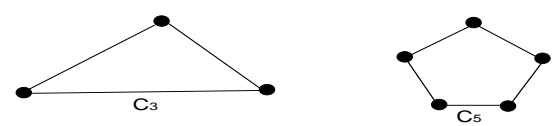

Gambar 3. Contoh graf siklus

4. Graf Bintang

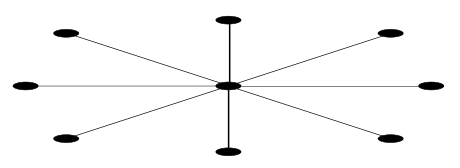

Gambar 4. Contoh graf bintang $S_{9}$

5. Graf Kipas

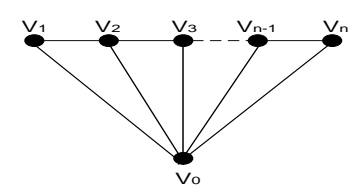

Gambar 5. Contoh graf kipas $F_{n}$

6. Graf Roda

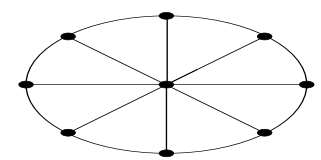

Gambar 6. Contoh graf roda $W_{8}$

\section{Graf Teratai}

Graf teratai dibentuk dari graf lengkap $K_{1}$ korona graf bintang $S_{n}$ kemudian titik $n-1$ pada graf bintang menghasilkan satu titik baru dan terhubung pada titik tengah graf bintang. Dengan demikian, graf teratai mempunyai $2 n+2$ titik dan $(2 n+1)$ sisi.

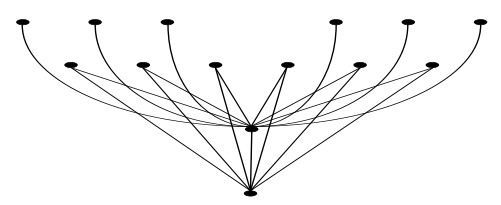

Gambar 7. Contoh graf teratain $=6$ 
8. $\quad$ Graf $K_{1} \odot\left(P_{n} \cup F_{n}\right)$

Graf $K_{1} \odot\left(P_{n} \cup F_{n}\right)$ adalah graf yang dibentuk dari graf $K_{1}$ korona graf lintasan $P_{n}$ gabung graf kipas $F_{n}$ yaitu $=K_{1} \odot\left(P_{n} \cup F_{n}\right)$, dengan demikian graf $K_{1} \odot\left(P_{n} \cup F_{n}\right)$ mempunyai $(2 n+2)$ titik dan $(4 n+1)$ sisi.

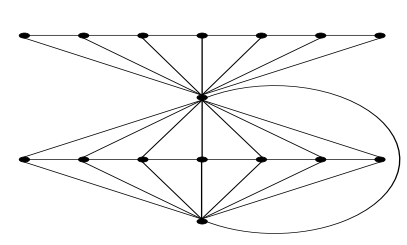

Gambar 8. Contoh graf $K_{1} \odot\left(P_{7} \cup F_{7}\right)$

9. $\quad$ Graf $K_{1} \odot t C_{n}$

Graf $K_{1} \odot t C_{n}$ adalah graf yang dibentuk dari graf $K_{1}$ korona beberapa graf siklus $t C_{n}$ yaitu $K_{1} \odot t C_{n}$, dengan demikian graf $K_{1} \odot t C_{n}$ mempunyai $(t n+1)$ titik dan $(2 t n)$ sisi.

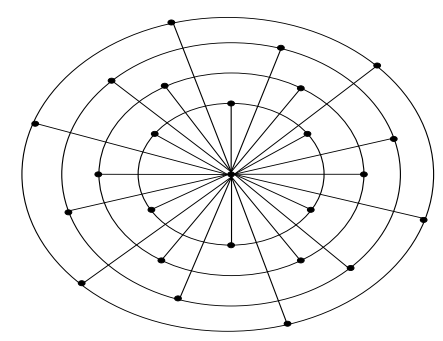

Gambar 9: Contoh graf $K_{1} \odot 4 C_{6}$

\subsection{Operasi Korona pada Graf}

Misalkan $G_{1}$ dan $G_{2}$ adalah dua buah graf sebarang. $G_{1}$ korona $G_{2},\left(G_{1} \odot G_{2}\right)$ adalah graf yang dibentuk dari graf $G_{1}$ dan graf $G_{2}$ dengan graf $G_{2}$ sebanyak order $G_{1}$, $\left(\left|G_{1}\right|\right)$, sebut $G_{2}{ }^{1}, G_{2}{ }^{2} \cdots, G_{2}{ }^{\left|G_{1}\right|}$ dengan cara menghubungkan semua titik di $G_{2}{ }^{(i)}$ ke satu titik $x_{i}$ di $G_{1}$, dengan $i=1,2, \cdots,\left|G_{1}\right|$. 


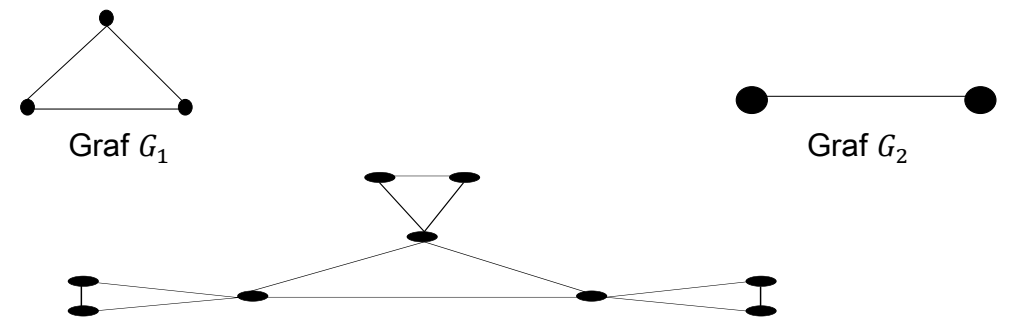

Gambar 10. Contoh graf $G_{1} \odot G_{2}$

\subsection{Pelabelan $L(2,1)$}

Pelabelan jarak dua, $\mathrm{L}(2,1)$ pada graf $\mathrm{G}$ dengan $\mathrm{p}$ titik dan q sisi adalah fungsi $f: V \rightarrow$ $N \cup\{0\}$ sedemikian sehingga memenuhi syarat :

1. $|f(u)-f(v)| \geq 2$, jika $d(u, v)=1$

2. $|f(u)-f(v)| \geq 1$, jika $d(u, v)=2$

$f: V \rightarrow\{0,1,2 \cdots, k\}$ dimana $\mathrm{k}$ adalah span dari pelabelan $\mathrm{L}(2,1)$. Span adalah label terbesar dari pelabelan $L(2,1)$ pada graf $\mathrm{G}$ atau $\mathrm{k} \in f(v)$ yang terbesar. Span dari suatu graf $\mathrm{G}$ bisa lebih dari satu. Minimal dari beberapa span graf $G$ dilambangkan dengan $\lambda(G)$ atau $\lambda(G)=$ $\min \{\operatorname{span}(G)\}$.

Proposisi 1 : Nilai $\lambda$ dari sebuah graf bintang $K_{1, \Delta}$ adalah $\Delta+1$, dimana $\Delta$ adalah derajat maksimum [3].

Proposisi $2: \lambda(H) \leq \lambda(G)$, untuk setiap subgraf $\mathrm{H}$ dari sebuah graf $\mathrm{G}$ [2].

\section{HASIL DAN PEMBAHASAN}

Pada bagian ini akan dibahas pelabelan L' $(2,1)$ pada graf kipas $\left(F_{n}\right)$, graf roda $\left(W_{n}\right)$, graf teratai, graf $K_{1} \odot\left(P_{n} \cup F_{n}\right)$ dan graf $K_{1} \odot t C_{n}$.

Definisi 1: Pelabelan $\mathrm{L}(2,1)$ pada graf $\mathrm{G}$ adalah fungsi $f: V \rightarrow\{0,1,2 \cdots, k\}$ yang memenuhi kondisi (1) $|f(u)-f(v)| \geq 2$, jika $d(u, v)=1,(2)|f(u)-f(v)| \geq 1$, jika $d(u, v)=2$. Bilangan $\mathrm{k}$ disebut span dari pelabelan $\mathrm{L}(2,1), f$, jika $\mathrm{k}$ adalah label titik terbesar atas pelabelan $\mathrm{L}(2,1), f$ tersebut. Notasi $\lambda(G)$ menunjukkan span terkecil atas semua pelabelan $L(2,1)$ pada graf $\mathrm{G}$. 


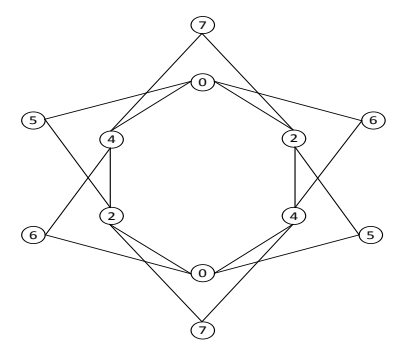

Gambar 11. Contoh pelabelan $\mathrm{L}(2,1)$ pada graf $D_{2}\left(C_{5}\right)$.

Definisi 2: Pelabelan $L(2,1)$ yang injektif disebut pelabelan $L^{\prime}(2,1)$ dan minimal span atas semua pelabelan $L^{\prime}(2,1)$ disebut $\lambda^{\prime}(G)$.

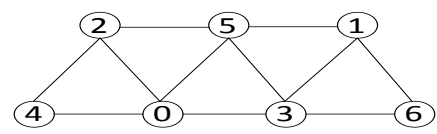

Gambar 12. Contoh pelabelan L'(2,1) pada graf $T\left(P_{4}\right)$

\subsection{Graf Kipas $\boldsymbol{F}_{\boldsymbol{n}}$}

Sebelum itu akan diberikan notasi titik dan sisi dari graf kipas $\left(F_{n}\right)$ untuk $n \geq 1$ adalah sebagai berikut :

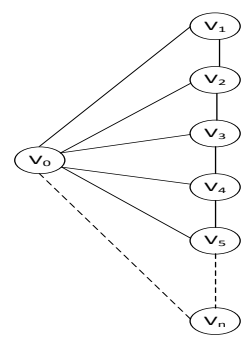

Gambar 13. Penotasian titik pada graf $F_{n}$

Berdasarkan Gambar 13 di atas dapat dinotasikan himpunan titik dan sisi pada graf $F_{n}$ untuk $n \geq 1$, yaitu :

$$
\begin{gathered}
V\left(F_{n}\right)=\left\{v_{i} \mid 0 \leq i \leq n\right\} \\
E\left(F_{n}\right)=\left\{e_{i} \mid 1 \leq i \leq n\right\} \text { dengan } e_{i}=v_{0} v_{i} ; 0 \leq i \leq n .
\end{gathered}
$$

Teorema 1: Graf Kipas dengan $n+1$ titik, $F_{n}$, mepunyai $\lambda^{\prime}\left(F_{n}\right)=n+1$ 


\section{Bukti :}

Pandang notasi titik dan sisi untuk graf $F_{n}$ pada gambar 13 akan ditunjukkan $\lambda^{\prime}\left(F_{n}\right) \leq$ $n+1$ yaitu dengan mengkonstruksi pelabelan $L^{\prime}(2,1)$ dari graf $F_{n}$ dengan span $n+1$. Definisikan fungsi injektiff: $V\left(F_{n}\right) \rightarrow\{0,1, \ldots, n+1\}$ sebagai berikut:

Untuk n ganjil:

$$
\begin{array}{ll}
f\left(v_{0}\right)=0 & ; i=1,2, \ldots,\left\lfloor\frac{n}{2}\right\rfloor \\
f\left(v_{i}\right)=2 i & \\
f\left(v_{\left[\frac{n}{2}\right\rceil}\right)=n+1 & ; i=\left\lceil\frac{n}{2}\right\rceil+1, \ldots, n \\
f\left(v_{i}\right)=2 i-5 &
\end{array}
$$

Untuk n genap:

$$
\begin{aligned}
& f\left(v_{0}\right)=0 \\
& f\left(v_{i}\right)=2 i \\
& f\left(v_{i}\right)=2 i-5 \\
& f\left(v_{n}\right)=n+1
\end{aligned}
$$

$$
\begin{aligned}
& ; i=1,2, \ldots, \frac{n}{2} \\
& ; i=\frac{n}{2}+1, \ldots, n-1
\end{aligned}
$$

Dapat diverifikasi bahwa fungsi $f$ memenuhi sifat pelabelan $\mathrm{L}(2,1)$ dalam Definisi 1 dan Definisi 2 dengan label terbesar adalah $n+1$. Oleh karena itu, $\lambda^{\prime}\left(F_{n}\right) \leq n+1$. Selanjutnya akan ditunjukkan $\lambda^{\prime}\left(F_{n}\right) \geq n+1$. Pandang graf $K_{1, n}$ adalah subgraf dari $F_{n}$ dan menurut Proposisi 1 dan 2, memberikan $\lambda^{\prime}\left(F_{n}\right) \geq \lambda^{\prime}\left(K_{1, n}\right)=n+1$ sehingga $\lambda^{\prime}\left(F_{n}\right) \geq n+1$. Jadi, $\lambda^{\prime}\left(F_{n}\right)=n+1$.

\subsection{Graf Roda $W_{n}$}

Sebelum itu akan diberikan notasi titik secara umum pada graf roda $\left(W_{n}\right)$ untuk $n \geq 1$ adalah sebagai berikut :

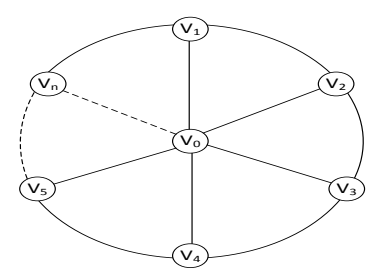

Gambar 14. Penotasian titik pada graf $W_{n}$

Berdasarkan Gambar 14 di atas dapat dinotasikan himpunan titik pada graf $W_{n}$ untuk $n \geq 1$, yaitu :

$$
\begin{gathered}
V\left(W_{n}\right)=\left\{v_{i} \mid 0 \leq i \leq n\right\} \\
E\left(W_{n}\right)=\left\{e_{i} \mid 1 \leq i \leq n\right\} \text { dengan } e_{i}=v_{0} v_{i} ; 0 \leq i \leq n .
\end{gathered}
$$


Teorema 2 : Graf Roda dengan $n+1$ titik, $W_{n}$, mepunyai $\lambda^{\prime}\left(W_{n}\right)=n+1$

Bukti :

Pandang notasi titik dan sisi untuk graf $W_{n}$ pada gambar 14 akan ditunjukkan $\lambda^{\prime}\left(W_{n}\right) \leq$ $n+1$ yaitu dengan mengkonstruksi pelabelan $L^{\prime}(2,1)$ dari graf $W_{n}$ dengan span $n+1$. Definisikan fungsi injektiff: $V\left(W_{n}\right) \rightarrow\{0,1, \ldots, n+1\}$ sebagai berikut :

Untuk n ganjil:

$f\left(v_{0}\right)=0$

$f\left(v_{i}\right)=2 i$

$; i=1,2, \ldots,\left\lfloor\frac{n}{2}\right\rfloor$

$f\left(v_{\left\lceil\frac{n}{2}\right\rceil}\right)=n+1$

$f\left(v_{i}\right)=2 i-5$

$; i=\left\lceil\frac{n}{2}\right\rceil+1, \ldots, n$

Untuk n genap:

$$
\begin{aligned}
& f\left(v_{0}\right)=0 \\
& f\left(v_{i}\right)=2 i \\
& f\left(v_{i}\right)=2 i-5 \\
& f\left(v_{n}\right)=n+1
\end{aligned}
$$$$
\text { ; } i=1,2, \ldots, \frac{n}{2}
$$$$
; i=\frac{n}{2}+1, \ldots, n-1
$$

Dapat di verifikasi bahwa fungsi $f$ memenuhi sifat pelabelan $L(2,1)$ dalam Definisi 1 dan Definisi 2 dengan label terbesar adalah $n+1$. Oleh karena itu, $\lambda^{\prime}\left(W_{n}\right) \leq n+1$. Selanjutnya akan ditunjukkan $\lambda^{\prime}\left(W_{n}\right) \geq n+1$. Pandang graf $K_{1, n}$ adalah subgraf dari $W_{n}$ dan menurut Proposisi 1 dan 2, memberikan $\lambda^{\prime}\left(W_{n}\right) \geq \lambda^{\prime}\left(K_{1, n}\right)=n+1$ sehingga $\lambda^{\prime}\left(W_{n}\right) \geq n+1$. Jadi, $\lambda^{\prime}\left(W_{n}\right)=n+1$.

\subsection{Graf Teratai $\boldsymbol{T}_{n}$}

Sebelum itu akan diberikan notasi titik dan sisi dari graf teratai $\left(T_{n}\right)$ untuk $n \geq 1$ adalah sebagai berikut :

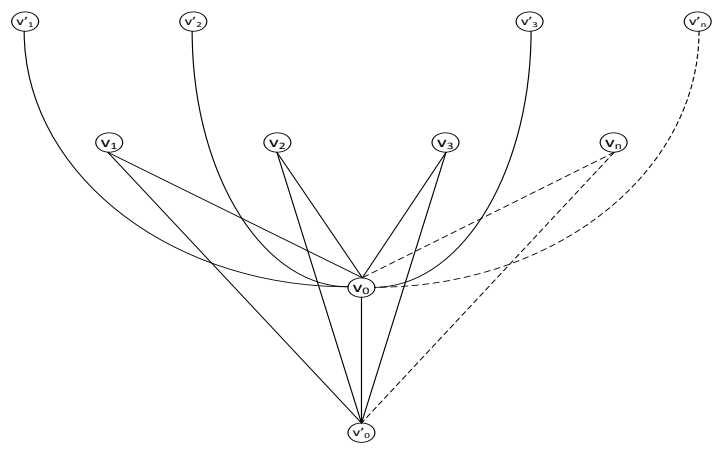

Gambar 15. Penotasian titik pada graf $T_{n}$ 
Berdasarkan Gambar 15 dapat dinotasikan himpunan titik pada graf $T_{n}$ untuk $n \geq 1$, yaitu :

$$
\begin{gathered}
V\left(T_{n}\right)=\left\{v_{i} \mid 0 \leq i \leq n\right\} \cup\left\{v_{i}^{\prime} \mid 0 \leq i \leq n\right\} \\
E\left(T_{n}\right)=\left\{e_{i} \mid 1 \leq i \leq n\right\} \text { dengan } e_{i}=v_{0} v_{i}^{\prime} ; 0 \leq i \leq n .
\end{gathered}
$$

Teorema 3 : Graf Teratai dengan $2 n+2$ titik, $T_{n}$, mepunyaii $\lambda^{\prime}\left(T_{n}\right)=2 n+2$

Bukti :

Pandang notasi titik dan sisi untuk graf $T_{n}$ pada gambar 15 akan ditunjukkan $\lambda^{\prime}\left(T_{n}\right) \leq$ $2 n+2$ yaitu dengan mengkonstruksi pelabelan L'(2,1) dari graf $T_{n}$ dengan span $2 n+2$. Definisikan fungsi injektiff: $V\left(T_{n}\right) \rightarrow\{0,1, \ldots, 2 n+2\}$ sebagai berikut :

$$
\begin{array}{ll}
f\left(v_{0}\right)=0 & \\
f\left(v_{i}\right)=i+1 & ; i=1,2, \ldots, n \\
f\left(v^{\prime}{ }_{0}\right)=2 n+2 & \\
f\left(v^{\prime}{ }_{i}\right)=i+n+1 & ; i=1,2, \ldots, n
\end{array}
$$

Dapat diverifikasi bahwa fungsi $f$ memenuhi sifat pelabelan $L(2,1)$ dalam Definisi 1 dan Definisi 2 dengan label terbesar adalah $2 n+2$. Oleh karena itu, $\lambda^{\prime}\left(T_{n}\right) \leq 2 n+2$. Selanjutnya akan ditunjukkan $\lambda^{\prime}\left(T_{n}\right) \geq 2 n+2$. Pandang graf $K_{1,2 n+1}$ adalah subgraf dari $T_{n}$ dan menurut Proposisi 1 dan 2, memberikan $\lambda^{\prime}\left(T_{n}\right) \geq \lambda^{\prime}\left(K_{1,2 n+1}\right)=2 n+2$ sehingga $\lambda^{\prime}\left(T_{n}\right) \geq 2 n+2$. Jadi, $\lambda^{\prime}\left(T_{n}\right)=2 n+2$.

\subsection{Graf $K_{1} \odot\left(P_{n} \cup F_{n}\right)$}

Sebelum itu akan diberikan notasi titik dan sisi dari graf $K_{1} \odot\left(P_{n} \cup F_{n}\right)$ untuk $n \geq 1$ adalah sebagai berikut :

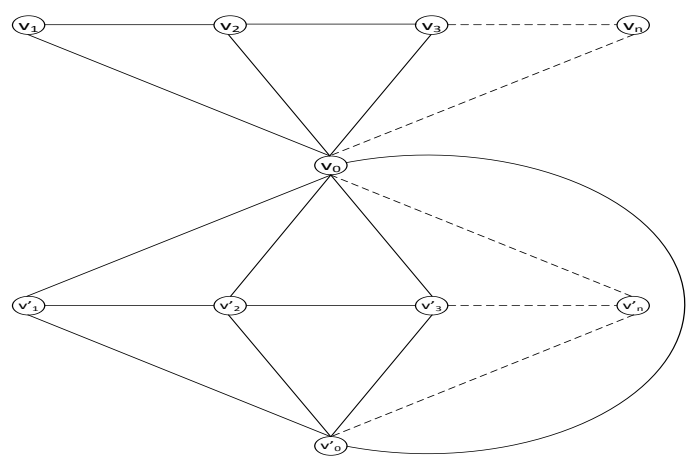

Gambar 16. Penotasian titik pada graf $K_{1} \odot\left(P_{n} \cup F_{n}\right)$ 
Berdasarkan Gambar 16 di atas dapat dinotasikan himpunan titik pada graf $K_{1} \odot\left(P_{n} \cup F_{n}\right)$ untuk $n \geq 1$, yaitu :

$$
\begin{gathered}
V\left(K_{1} \odot\left(P_{n} \cup F_{n}\right)\right)=\left\{v_{i} \mid 0 \leq i \leq n\right\} \cup\left\{v^{\prime}{ }_{i} \mid 0 \leq i \leq n\right\} \\
E\left(T_{n}\right)=\left\{e_{i} \mid 1 \leq i \leq n\right\} \text { dengan } e_{i}=v_{0} v^{\prime}{ }_{i} ; 0 \leq i \leq n .
\end{gathered}
$$

Teorema 4 : Graf $K_{1} \odot\left(P_{n} \cup F_{n}\right)$ dengan $2 n+2$ titik, $K_{1} \odot\left(P_{n} \cup F_{n}\right)$, mepunyai $\lambda^{\prime}\left(K_{1} \odot\left(P_{n} \cup\right.\right.$

$$
\left.\left.F_{n}\right)\right)=2 n+2
$$

\section{Bukti :}

Pandang notasi titik dan sisi untuk graf $K_{1} \odot\left(P_{n} \cup F_{n}\right)$ pada gambar 16 akan ditunjukkan $\lambda^{\prime}\left(K_{1} \odot\left(P_{n} \cup F_{n}\right)\right) \leq 2 n+2$ yaitu dengan mengkonstruksi pelabelan L'(2,1) dari graf $K_{1} \odot\left(P_{n} \cup\right.$ $\left.F_{n}\right)$ dengan span $2 n+2$. Masukkan fungsi injektiff: $V\left(K_{1} \odot\left(P_{n} \cup F_{n}\right)\right) \rightarrow\{0,1, \ldots, 2 n+2\}$ sebagai berikut:

$$
\begin{array}{ll}
f\left(v_{0}\right)=0 & \\
f\left(v_{i}\right)=2 i+1 & ; i=1,2, \ldots, n \\
f\left(v^{\prime}{ }_{0}\right)=2 & ; i=1,2, \ldots, n-1 \\
f\left(v^{\prime}{ }_{i}\right)=2 i+2 & \\
f\left(v_{n}\right)=2 n+2 &
\end{array}
$$

Dapat diverifikasi bahwa fungsi $f$ memenuhi sifat pelabelan $L(2,1)$ dalam Definisi 1 dan Definisi 2 dengan label terbesar adalah $2 n+2$. Oleh karena itu, $\lambda^{\prime}\left(K_{1} \odot\left(P_{n} \cup F_{n}\right)\right) \leq 2 n+2$. Selanjutnya akan ditunjukkan $\lambda^{\prime}\left(K_{1} \odot\left(P_{n} \cup F_{n}\right)\right) \geq 2 n+2$. Pandang graf $K_{1,2 n+1}$ adalah subgraf dari $K_{1} \odot\left(P_{n} \cup F_{n}\right)$ dan menurut Proposisi 1 dan 2, memberikan $\lambda^{\prime}\left(K_{1} \odot\left(P_{n} \cup F_{n}\right)\right) \geq$ $\lambda^{\prime}\left(K_{1,2 n+1}\right)=2 n+2$ sehingga $\lambda^{\prime}\left(K_{1} \odot\left(P_{n} \cup F_{n}\right)\right) \geq 2 n+2$. Jadi, $\lambda^{\prime}\left(K_{1} \odot\left(P_{n} \cup F_{n}\right)\right)=2 n+2$.

\subsection{Graf $K_{1} \odot t C_{n}$}

Sebelum itu akan diberikan notasi titik dan sisi dari graf $K_{1} \odot t C_{n}$ untuk $n \geq 1$ dan $t \geq 1$ adalah sebagai berikut :

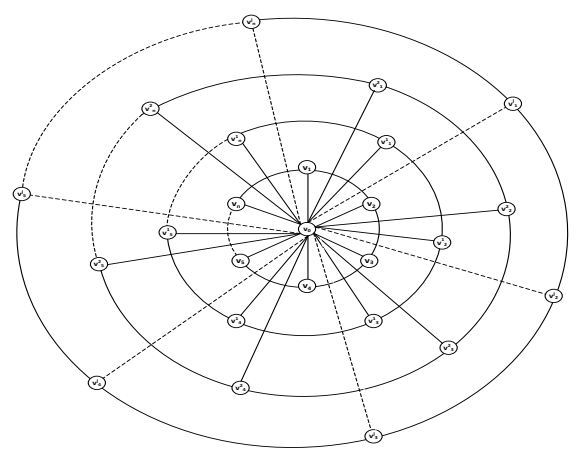

Gambar 17. Penotasian titik pada graf $K_{1} \odot t C_{n}$ 
Berdasarkan Gambar 17 di atas dapat dinotasikan himpunan titik pada graf $K_{1} \odot t C_{n}$ untuk $n \geq 1$ dan $t \geq 1$, yaitu :

$$
\begin{gathered}
V\left(K_{1} \odot t C_{n}\right)=\left\{v_{0}, v_{i}^{j} \mid 0 \leq i \leq n \text { dan } 0 \leq j \leq t-1\right\} \\
E\left(K_{1} \odot t C_{n}\right)=\left\{e_{i} \mid 1 \leq i \leq n\right\} \text { dengan } e_{i}=v_{0} v_{i}^{j} ; 0 \leq i \leq n .
\end{gathered}
$$

Teorema 5 : Graf $K_{1} \odot t C_{n}$ dengan $t n+1$ titik, $K_{1} \odot t C_{n}$ mempunyai $\lambda^{\prime}\left(K_{1} \odot t C_{n}\right)=t n+1$

Bukti :

Pandang notasi titik dan sisi untuk graf $K_{1} \odot\left(P_{n} \cup F_{n}\right)$ pada gambar 17 akan ditunjukkan $\lambda^{\prime}\left(K_{1} \odot t C_{n}\right) \leq t n+1$ yaitu dengan mengkonstruksi pelabelan L' $(2,1)$ dari graf $K_{1} \odot t C_{n}$ dengan span $t n+1$. Masukkan fungsi injektiff: $V\left(T_{n}\right) \rightarrow\{0,1, \ldots, t n+1\}$ sebagai berikut :

Untuk n ganjil:

$$
\begin{array}{ll}
f\left(v_{0}\right)=0 & ; i=1,2, \ldots,\left\lceil\frac{n}{2}\right\rceil \\
f\left(v_{i}\right)=2 i & ; i=\left\lceil\frac{n}{2}\right\rceil+1, \ldots, n \\
f\left(v_{i}\right)=2 i-n & ; i=1,2, \ldots, n \text { dan } j=1,2, \ldots, t \\
f\left(v_{i}^{j}\right)=f\left(v_{i}\right)+j n & \\
f\left(v_{\left\lceil\frac{n}{2}\right\rceil}^{t}\right)=t n+1 &
\end{array}
$$

Untuk n genap:

$$
\begin{aligned}
& f\left(v_{0}\right)=0 \\
& f\left(v_{i}\right)=2 i \\
& f\left(v_{i}\right)=2 i-n+1 \\
& f\left(v_{i}^{j}\right)=f\left(v_{i}\right)+j n \\
& f\left(v_{n}^{t}\right)=t n+1
\end{aligned}
$$

$$
\begin{aligned}
& ; i=1,2, \ldots, \frac{n}{2} \\
& ; i=\frac{n}{2}+1, \ldots, n \\
& ; i=1,2, \ldots, n \text { dan } j=1,2, \ldots, t
\end{aligned}
$$

Dapat diverifikasi bahwa fungsi $f$ memenuhi sifat pelabelan $L(2,1)$ dalam Definisi 1 dan Definisi 2 dengan label terbesar adalah $t n+1$. Oleh karena itu, $\lambda^{\prime}\left(K_{1} \odot t C_{n}\right) \leq t n+1$. Selanjutnya akan ditunjukkan $\lambda^{\prime}\left(K_{1} \odot t C_{n}\right) \geq t n+1$. Pandang graf $K_{1, t n}$ adalah subgraf dari $K_{1} \odot t C_{n}$ dan menurut Proposisi 1 dan 2, memberikan $\lambda^{\prime}\left(K_{1} \odot t C_{n}\right) \geq \lambda^{\prime}\left(K_{1, t n}\right)=2 n+2$ sehingga $\lambda^{\prime}\left(K_{1} \odot t C_{n}\right) \geq t n+1$. Jadi, $\lambda^{\prime}\left(K_{1} \odot t C_{n}\right)=t n+1$.

\section{KESIMPULAN}

Berdasarkan hasil penelitian yang telah dilakukan, dapat disimpulkan :

1. Graf kipas $F_{n}$ adalah $L^{\prime}(2,1)$ dengan $n \geq 5, \lambda^{\prime}\left(F_{n}\right)=n+1$

2. Graf roda $W_{n}$ adalah $L^{\prime}(2,1)$ dengan $n \geq 5, \lambda^{\prime}\left(W_{n}\right)=n+1$

3. Graf teratai $T_{n}$ adalah $L^{\prime}(2,1)$ dengan $n \geq 3, \lambda^{\prime}\left(T_{n}\right)=2 n+2$

4. Graf $K_{1} \odot\left(P_{n} \cup F_{n}\right)$ adalah $L^{\prime}(2,1)$ untuk $n \geq 3, \lambda^{\prime}\left(K_{1} \odot\left(P_{n} \cup F_{n}\right)\right)=2 n+2$

5. Graf $K_{1} \odot t C_{n}$ adalah L'(2,1) untuk $n \geq 5$ dan $t \geq 3, \lambda^{\prime}\left(K_{1} \odot t C_{n}\right)=t n+1$ 


\section{DAFTAR PUSTAKA}

[1]. Didi, S. dan Nanang, P, 2008, Pengetahuan Dasar Teori Graph, Binadarma, , Palembang, 2.

[2]. G. Chang and D. Kuo, The L(2,1)-labelling problem on graphs, SIAM J. Discrete Math, 9(2), 1996, 309-316.

[3]. J. Griggs and R. Yeh, 1992, Labeling graph with a condition at distance 2, SIAM J. Discrete Math, 5, 586-595.

[4]. Vadya, S. K., Vihol, P. L., Dani, N. A., Bantva, D. D, 2011, Distance two labeling of some total graph, Gen. Math. Notes, 3, 100-107.

[5]. Wilson, R. J and Watkins, J.J, 1990, Graphs : An Introductory Approach a First Course in Discrete Mathematics., John Willy and Sons, Inc, New York. 